\title{
Efeito de níveis de severidade e incidência da ferrugem-da-folha e ferrugem-do-colmo no rendimento de linhagens de aveia ${ }^{(1)}$
}

\author{
Eduardo Caierão(2), Fernando Irajá Félix de Carvalho(3), Elmar Luiz Floss ${ }^{(4)}$, \\ Carlos Danilo Sánchez-Chacón ${ }^{(3)}$, Claudir Lonrecetti( ${ }^{(3)}$ e Volmir Marchioro(5)
}

\begin{abstract}
Resumo - A introdução de germoplasma representa uma das alternativas para o aumento da variabilidade em aveia (Avena sativa L.), favorecendo o processo de seleção. Os objetivos deste estudo foram: a) selecionar genótipos de aveia com potencial de rendimento e adaptação às condições do Estado do Rio Grande do Sul; b) determinar a relação entre as moléstias ferrugem-da-folha e ferrugem-do-colmo sobre o rendimento; c) estimar a relação entre os critérios: severidade e incidência, para diagnóstico da intensidade das moléstias. Foram avaliados 57 genótipos de aveia com relação ao rendimento de grãos e outros caracteres. Os genótipos foram classificados de acordo com o desvio-padrão sobre a média e os dados dos caracteres considerados submetidos à análise de correlação e regressão. Somente três genótipos introduzidos foram considerados promissores. A correlação entre ferrugem-da-folha e o rendimento foi significativa, diferentemente da ferrugem-do-colmo. A regressão da severidade em virtude da incidência das duas moléstias evidenciou comportamento quadrático, embora a relação linear tenha sido observada em níveis reduzidos de incidência. Pelo tipo de reação às moléstias, os genótipos selecionados são de alto valor para o programa de melhoramento da aveia. O critério incidência pode substituir com eficiência a severidade em níveis reduzidos de epidemia, facilitando o diagnóstico no campo.
\end{abstract}

Termos para indexação: seleção, genótipos, doenças das plantas, resistência a doenças, métodos de melhoramento.

\section{Effect of severity and incidence levels of crown rust and stem rust on yield of oat genotypes}

\begin{abstract}
Germoplasm introduction represents an alternative to increase oat (Avena sativa L.) variability, favoring selection. The objectives of this study were: a) to select oat lines with high grain yield and adaptation to State conditions; b) to determine the relationship between crown and stem rust with grain yield; c) to estimate the relationship between severity and incidence rules as tools to diagnose disease intensity. Fifty seven oat lines were evaluated for grain yield and other characters. The lines were classified using the mean standard deviation and the data was submitted to correlation and regression analyses. Only three introduced lines looked promising. The correlation between crown rust and grain yield was significant, differently from stem rust. Severity to incidence regression of diseases showed quadratic behaviour, although linear relations were observed in low incidence levels. From disease reaction type, the selected lines are valuable to oat breeding programs. Incidence rule can efficiently replace the severity rule at low epidemic levels, facilitating field diagnostics.
\end{abstract}

Index terms: selection, genotypes, plant diseases, disease resistance, breeding methods.

\footnotetext{
(1) Aceito para publicação em 15 de fevereiro de 2000.

(2) CEC Passo do Silva, Primeiro Subdistrito, Caixa Postal 33, CEP 96610-000 Encruzilhada do Sul, RS. E-mail: mnec@brahma.com.br

(3) UFPel, Faculdade de Agronomia Eliseu Maciel (FAEM), Dep. de Fitotecnia, Caixa Postal 354, CEP 96001-970 Pelotas, RS
}

Bolsista do CNPq. E-mail: carvalho@ufpel.tche.br, sanchez@ufpel.tche.br, claudir@ufpel.tche.br

(4) Universidade de Passo Fundo (UPF), Faculdade de Agronomia e Medicina Veterinária (FAMV), Caixa Postal 271, CEP 99001-970 Passo Fundo, RS. E-mail: floss @ upf.tche.br

(5) UFPel, FAEM, Bolsista da Capes.

E-mail: volmirsm@ufpel.tche.br 


\section{Introdução}

A elevada produção e demanda por grãos de aveia no Brasil, nos últimos anos, tem sido conseqüência do alto potencial de rendimento das cultivares, alcançado por meio de um programa de melhoramento eficiente sobre a espécie, além de outras características, como a garantia de comercialização do produto e a viabilidade em termos de sustentabilidade agrícola.

Até pouco tempo, os programas de melhoramento tinham enfoque especial para a seleção positiva de genótipos (seleção de genótipos com características agronômicas promissoras), quase sempre a partir do rendimento de grãos. Este procedimento era especialmente responsivo, já que o potencial de rendimento da cultura ainda era reduzido e, portanto, todo incremento tornava-se significativo e, na maioria das vezes, condicionava o lançamento de uma nova cultivar. Com o passar dos anos, a substituição das cultivares lançadas no mercado passou a ser mais lenta, pela maior dificuldade de ganho genético em rendimento de grãos em comparação com as cultivares disponíveis e, também, pela perda de resistência às principais moléstias, como ferrugem-da-folha e ferrugem-do-colmo. Neste sentido, a variabilidade dos patógenos, causada principalmente por mutação, chegando a 1 mutante a cada 2.000 esporos produzidos de Puccinia coronata f. sp. avenae (Zimmer et al., 1963), e as condições de ambiente (Roelfs et al., 1992), que elevam a severidade das moléstias, são, sem dúvida, as causas da ausência ou do reduzido progresso no aumento do rendimento de grãos. Assim, a seleção negativa (seleção baseada na eliminação de genótipos indesejados), buscando a manutenção de genótipos resistentes e, recentemente, a seleção de genótipos que apresentam resistência parcial (resistência conferida, muitas vezes, pelo valor aditivo de vários genes em relação às raças de um patógeno), parecem ser boas alternativas de seleção.

Uma das possibilidades para o desenvolvimento de genótipos superiores com reação de resistência elevada é a hibridação, cruzando-se genótipos produtivos com outros, resistentes às moléstias. Além desta, a introdução de germoplasma em homozigose, de outros programas, é uma boa alternativa para iden- tificar constituições genéticas promissoras, já que geralmente são genótipos elite no local de origem, resultado de cruzamentos específicos que objetivam a resistência às principais moléstias, qualidade, e elevado rendimento de grãos. O maior obstáculo na introdução de novos genótipos é sua adaptação às novas condições (Borém, 1998); assim, o ambiente, onde ocorrem novas raças dos fungos fitopatogênicos passa a ser o parâmetro mais importante da seleção.

Das moléstias que atacam a cultura da aveia, a ferrugem-da-folha é a de maior importância (Simons \& Murphy, 1961). Perdas superiores a 50\% têm sido encontradas por Martinelli et al. (1994), em algumas regiões do sul do Brasil. A importância da moléstia ferrugem-da-folha com relação ao rendimento de grãos de aveia pode ser comprovada a partir do seu limiar de dano econômico (LDE) sobre a espécie, como descrito por Martinelli et al. (1994), em que severidade de apenas 5\% ou incidência de $15-20 \%$ (Reis, 1998) já representa reduções na produtividade de grãos, por unidade de área, iguais ao custo do tratamento químico.

Conforme Reis et al. (1996), com freqüência há dificuldades na interpretação e no uso do critério severidade da moléstia (porcentagem de área foliar infectada com pústulas do patógeno) sobre a lavoura para decidir o momento mais adequado da aplicação do fungicida, por ser um critério subjetivo (pois diferentes avaliações sobre uma mesma folha podem revelar diferenças na porcentagem de área foliar infectada). Para Amorim (1995), o parâmetro incidência da moléstia (porcentagem de infecção da moléstia na lavoura, considerando plantas individuais) é de maior simplicidade e precisão, além de fornecer uma idéia clara da intensidade da moléstia, sem nenhuma subjetividade, pois avalia apenas a presença ou ausência de pústulas. Entretanto, segundo o mesmo autor, a severidade é o parâmetro mais apropriado para moléstias foliares como as ferrugens e oídio (Erysiphe graminis f. sp. avenae). Em trigo, o mesmo autor encontrou correlação de 0,62 entre a severidade e a incidência da ferrugem-da-folha, revelando possibilidade de utilização do critério incidência para a avaliação. A consideração de ambos os critérios para a determinação da intensidade das moléstias é importante, já que em fase avançada da epidemia, apenas a incidência não é suficiente para 
sua quantificação. Além disso, a incidência não é um bom parâmetro para indicar o ponto inicial do tratamento químico para genótipos com resistência progressiva "slow rusting", já que a incidência pode ser alta e a severidade manter-se em níveis que não justificam o controle.

Desta maneira, o trabalho teve como objetivos: a) caracterizar fenotipicamente os genótipos introduzidos de aveia, a partir do rendimento de grãos, adaptação e reação às moléstias ferrugem-da-folha $\mathrm{e}$ ferrugem-do-colmo; b) verificar a correlação entre a incidência da ferrugem-da-folha e ferrugem-do-colmo sobre o rendimento, e c) determinar o grau de correlação entre a severidade e incidência das moléstias sobre a cultura.

\section{Material e Métodos}

Em 1998 foi introduzida na área experimental do Centro Agropecuário da Palma (UFPel), no Município de Capão do Leão, em solo Podzólico Vermelho-Amarelo, uma coleção de 76 genótipos de aveia em homozigose (não-segregantes), desenvolvidos por universidades norte-americanas, juntamente com a testemunha UPF 16, em quatro repetições. Dos 76 genótipos, somente 57 foram avaliados, pois os demais não alcançaram o período da floração, evidenciando baixa adaptação.

Cada genótipo foi semeado em duas linhas, de $2,5 \mathrm{~m} \times 0,2 \mathrm{~m}$, com espaços de $0,4 \mathrm{~m}$ entre si. A adubação do ensaio foi realizada com base na análise de solo $(300 \mathrm{~kg} / \mathrm{ha}$ da fórmula 5-20-20), e o controle de plantas daninhas, por meio de capinas manuais. Realizou-se, também, uma aplicação de uréia $(100 \mathrm{~kg} / \mathrm{ha})$ no estádio médio de afilhamento. Para a expressão dos níveis de resistência à ferrugem-da-folha e ferrugem-do-colmo não se efetuou a aplicação de fungicidas sobre a coleção.

As leituras da incidência e da severidade das moléstias foram realizadas na fase de elongação (estágio 6 e 7) e na floração (estágio 105), para a ferrugem-da-folha (FF Puccinia coronata f. sp. avenae) e, somente na floração para a ferrugem-do-colmo (FC - Puccinia graminis f. sp. avenae), de acordo com a escala fenológica de Feekes, ilustrado por Large (1954). A incidência das moléstias foi calculada a partir de uma amostragem de 20 folhas e 20 colmos por repetição em cada genótipo, respectivamente, para FF e FC, em que foi avaliada a porcentagem de plantas com infecção destas moléstias. A amostragem foi aleatória, porém de perfilhos diferentes. Para a severidade, utilizou-se do aplicativo compu- tacional DISTRAIN (Disease Training), desenvolvido por Tomerlin \& Howell (1988), como parâmetro de cobertura da área foliar (\% de área foliar lesionada). A severidade foi determinada pela média da área infectada pelas moléstias nas 20 folhas e colmos.

Os dados de incidência e severidade da ferrugem-dafolha e ferrugem-do-colmo foram submetidos a análise de correlação com o rendimento e, entre si, em relação às moléstias. A análise foi realizada a partir dos dados transformados, utilizando-se o procedimento $\log (\mathrm{x}+1)$, em que $x$ equivale à nota de incidência ou severidade. Na regressão polinomial da severidade em função da incidência, aplicou-se a transformação logarítmica para severidade, descrita por James \& Shih (1973), utilizando-se a seguinte expressão:

$$
\mathrm{S}=\mathrm{b} \times \log \left(1-\frac{\mathrm{I}}{100}\right), \text { onde }
$$

$\mathrm{S}=$ severidade, $\mathrm{I}=$ incidência,

$\mathrm{b}=$ coeficiente de regressão obtido através de uma linha sobre a origem do gráfico cartesiano.

Conforme Rouse et al. (1981) citado por Reis et al. (1996), a partir deste modelo, os dados da severidade, sujeitos à variação visual no momento de sua avaliação são transformados, enquanto os objetivos da incidência (presença ou ausência de pústulas), não. A partir dos dados transformados da severidade e originais da incidência, foram ajustadas equações de regressão polinomial da primeira em função da segunda, no que diz respeito a ambas as moléstias, determinando-se o grau de maior coeficiente de determinação $\left(\mathrm{R}^{2}\right)$. Para tal procedimento, foi utilizado o aplicativo computacional Excel 7.0 (Office 97).

$\mathrm{O}$ efeito da incidência e severidade das moléstias foi avaliado sobre o rendimento de grãos (RG), peso de panícula (PP) e peso de mil grãos (PMG). O rendimento de grãos foi obtido segundo o procedimento utilizado pelas Universidades de Passo Fundo e do Rio Grande do Sul, mediante colheita, trilha, desaristamento e pesagem dos grãos. Os resultados foram transformados para $\mathrm{kg} / \mathrm{ha}$. O peso de panícula foi obtido a partir de uma amostragem aleatória de 10 panículas de cada parcela; as panículas foram pesadas, e determinou-se a média da população. O peso de mil grãos foi estimado multiplicando-se o peso de 400 grãos por 2,5, conforme o método utilizado pelo programa de pesquisa de aveia da Universidade Federal do Rio Grande do Sul e Universidade de Passo Fundo.

Os genótipos foram classificados como: superiores (valores maiores que a média, mais um desvio-padrão), e inferiores (valores menores que a média, menos um desviopadrão). 


\section{Resultados e Discussão}

Na Tabela 1 estão representados os genótipos avaliados, com suas respectivas genealogias. Houve grande amplitude de rendimento de grãos por unidade de área dos genótipos avaliados, o que, possivelmente, demonstra diferentes graus de adaptação às condições de Pelotas, como resultado da expressão diferenciada das constituições genéticas ao ambiente. Poucos genótipos apresentaram rendimento superior à média do experimento, mais um desvio-padrão, entre eles, duas repetições da testemunha UPF 16 e as linhagens $68,17,69,4,25,9$ e 50 (Tabela 2). O efeito do ambiente diferenciado em relação às condições do local de origem do germoplasma estudado fica evidente, tendo em vista os baixos rendimentos obtidos por muitos genótipos. Este desempenho vai ao encontro de Borém (1998), que ressalta baixa produtividade em introduções de germoplasma, principalmente onde as condições de ambiente forem extremas entre o local de origem e o de avaliação. Dos sete genótipos superiores quanto ao RG, somente as linhas 4 e 9, além da testemunha UPF 16, estão relacionadas com o germoplasma desenvolvido em programas brasileiros, especialmente de Passo Fundo e Porto Alegre, RS. Esta condição pode ser um indicativo do alto rendimento apresentado, e ter contribuído para ele. As demais linhagens que formaram o grupo de destaque, embora não te- nham apresentado relação com genótipos nacionais, evidenciaram ótima constituição genética para produtividade e um potencial de adaptação às condições experimentais.

Com relação ao PMG, dos genótipos que foram superiores em rendimento de grãos, o 68, 69 e 17 foram os únicos que também demonstraram comportamento superior, relativo a este caráter (Tabela 2). A expressão da variável evidenciou amplitude de comportamento dos genótipos. Na maioria das vezes, a classificação como superior para este caráter (PMG) não correspondeu ao mesmo comportamento em RG.

A variável PP revelou comportamento superior dos genótipos 68, 69 e 17, da mesma forma que para RG e PMG. Conseqüentemente, estes genótipos foram os únicos a apresentarem desempenho superior nos três caracteres, constituindo-se em forte indicativo de potencialidade destas constituições genéticas e expressão da capacidade de adaptação ao ambiente teste (Tabela 2).

Até a fase de elongação, grande parte dos genótipos avaliados demonstraram reação de alta resistência à ferrugem-da-folha (Tabela 3). Esta reação caracterizou-se pela ausência de pústulas ou traços da moléstia. Cerca de 20 genótipos atingiram o LDE para a cultura, que corresponde a $5 \%$ de severidade ou 15\%-20\% de incidência (Martinelli et al., 1994; Reis, 1998). Na mesma Tabela 3, pode ser

Tabela 1. Genealogia dos genótipos de aveia introduzidos em 1998, através do programa de intercâmbio com a Quaker. FAEM/UFPel, 1998.

\begin{tabular}{|c|c|}
\hline Identificação $^{(1)}$ & Genealogia \\
\hline 1 & UPF 16 (testemunha) \\
\hline 3 & Coronado2/Cortez3/Pendek/ME1563 \\
\hline $4^{(2)}$ & UPF 79239-1 \\
\hline 5 & Ogle/MO 07468/centennial \\
\hline 6 & Coronado $^{2} /$ Cortez $^{3} /$ Pendek/ME1563 \\
\hline 8 & FL501 Res. Sel \\
\hline $9^{(2)}$ & 422/90 Sat-4 (Guaíba Sel 1 Resel) \\
\hline 10 & Carma \\
\hline 11 & 79Bord/Keyna SR/RAMO 386*2 \\
\hline 12 & TAMO 386 Resel. \\
\hline 13 & Coron $2 / \mathrm{Ctz}^{3} /$ Pendek//ME1563/TAMO 386 \\
\hline 14 & Mitchell/Tx83Ab2923 \\
\hline 15 & Contennial/Hazel/2/Ogle \\
\hline
\end{tabular}


Tabela 1. Continuação.

\begin{tabular}{|c|c|}
\hline Identificação $^{(1)}$ & Genealogia \\
\hline 17 & 79 Bordanavel/Keyna SR \\
\hline 18 & WI X6396-1/MN87183 \\
\hline 19 & Obee/Midsouth//5*Starter/3/87183 \\
\hline 20 & MN95260/C7-4 \\
\hline 21 & UPF 16 (testemunha) \\
\hline 22 & CT-21 Starter//o/n/3/Starter \\
\hline 23 & MN94143/Ogle/Amagalon \\
\hline 24 & Ogle/amagalon/MN94233 \\
\hline 25 & MN94266/Ogle/Amagalon \\
\hline 26 & MN95260/Ogle/amagalon \\
\hline 27 & Ogle/Amagalon/e/Troy//MN84231/MN87180 \\
\hline 29 & PUR8640AI-31-17M184-0-6 \\
\hline 30 & Troy/starter-1"WOMPe" \\
\hline 31 & Amagalon $/ 6 *$ Starter//2*Premier \\
\hline 32 & Amagalon $/ 6 *$ Starter $/ / 2 *$ Premier \\
\hline 33 & Ogle-1//Obee/Midsouth/3/Jerry \\
\hline 34 & PUR76178DI/3/WI.1961-1/NO//PUR72288 \\
\hline 35 & NEWDAK/86209 \\
\hline 36 & PREMIR/81127//PUR76178BI \\
\hline 37 & HORICON/MN84231//MN86108 \\
\hline 38 & MILTON/TROY \\
\hline 39 & 86228//P7869DI/MN88231 \\
\hline 40 & STARTER/MN84231 \\
\hline 41 & UPF 16 (testemunha) \\
\hline 42 & MN84231//HORICON/TROY \\
\hline 43 & RODEO \\
\hline 44 & STARTER5/OBEE//MIDSOUTH/3/STARTER3/STARTER \\
\hline 45 & HORICON/PUR76178DI \\
\hline 48 & DON/4/SD820188/STARTER/3/IL753402//TUCKER/ND810106 \\
\hline 49 & NOBLE//DAL/NOD.70/3/ND821456/4/MN81229/5/DON \\
\hline 50 & SD86067*/3/SPEAR/KELSEY//DUMONT \\
\hline 51 & ND863328/ND873536 \\
\hline 52 & ND879845/ND890358 \\
\hline 53 & TROY/STARTER-1'WONPe' \\
\hline 54 & DANES/STARTER-1'WOMPe' \\
\hline 55 & 89127/3/OBEE/MIDSOUTH//5*OGLE \\
\hline 56 & ARMOR/JERRY \\
\hline 57 & C5-13/C5-21//IL86-5262 \\
\hline 58 & PUR8640A1-31-1/MN84-0-6 \\
\hline 59 & TROY/M184-0-6 \\
\hline 60 & OGLE-1//OBEE/MIDSOUTH/3/JERRY \\
\hline 61 & UPF 16 (testemunha) \\
\hline 62 & 86228/WISC.X5673-2 \\
\hline 63 & MILTON/3/OBEE/MIDSOUTH//5*OGLE \\
\hline 64 & WIX6396-1/92104 \\
\hline 67 & BLAZE \\
\hline 68 & OA974-1 \\
\hline 69 & OA973-1 \\
\hline
\end{tabular}

(1) 34 a 69: identificadas por Don McVey (slow-rusting), citado por Forsberg et al. (1998). ${ }^{(2)}$ Linhagens desenvolvidas a partir de germoplasma nacional. 
observado, a partir das leituras realizadas na elongação e floração, que a severidade de FF aumentou de modo geral, de acordo com o desenvolvimento das plantas, embora muitos genótipos tenham demonstrado resistência. Pelos dados incluídos na Tabela 3, a testemunha UPF 16 expressou acréscimos de $25 \%$ e $30 \%$ na severidade de FF da primeira para a segunda avaliação em duas repetições, ao passo que houve genótipos que apresentaram reação de resistência máxima. Considerando esta variável independentemente do rendimento, as linhagens 24, 25, 31 e 32, entre outras que não apresentaram pústulas ou desenvolveram apenas traços poderiam ser indicadas promissoras. Entretanto, a reação de resistência destes genótipos não corresponde a um elevado rendimento final, o que pode ser comprovado pela inclusão no grupo superior quanto ao RG, somente de uma das linhas que não apresentaram pústulas (linha 25). As linhas 68, 69 e 25 não atingiram o LDE, e obtiveram desempenho superior quanto ao rendimento de grãos, assim, como a linha 17, que não ultrapassou a $10 \%$ de incidência e severidade. As demais superiores quanto ao rendimento não ultrapassaram a $30 \%$ de severidade.

Pela Tabela 1, pode ser verificado que as linhas 68 e 69 pertencem a um grupo de linhagens denominadas de "slow-rusting", que apresentaram lento estabelecimento e desenvolvimento da moléstia FF; por

Tabela 2. Rendimento de grãos (RG), peso de mil grãos (PMG) e peso de panícula (PP) de genótipos introduzidos de aveia. FAEM/UFPel, $1998^{(1)}$.

\begin{tabular}{cccl}
\hline Identificação & RG $(\mathrm{kg} / \mathrm{ha})$ & $\mathrm{PMG}(\mathrm{g})$ & $\mathrm{PP}(\mathrm{g})$ \\
\hline 68 & $3.944 \mathrm{~S}$ & $130,8 \mathrm{~S}$ & $4,10 \mathrm{~S}$ \\
17 & $3.701 \mathrm{~S}$ & $27,8 \mathrm{~S}$ & $4,48 \mathrm{~S}$ \\
69 & $3.595 \mathrm{~S}$ & $30,4 \mathrm{~S}$ & $3,95 \mathrm{~S}$ \\
21 & $3.484 \mathrm{~S}$ & 24,5 & 2,81 \\
4 & $3.146 \mathrm{~S}$ & 21,0 & $3,51 \mathrm{~S}$ \\
1 & $3.140 \mathrm{~S}$ & 24,6 & 2,69 \\
25 & $3.130 \mathrm{~S}$ & 22,3 & 2,45 \\
9 & $2.965 \mathrm{~S}$ & 26,3 & 3,18 \\
50 & $2.928 \mathrm{~S}$ & 22,9 & $4,33 \mathrm{~S}$ \\
54 & 2.678 & 25,6 & 3,10 \\
35 & 2.669 & 26,5 & $4,23 \mathrm{~S}$ \\
26 & 2.549 & 25,5 & 2,71 \\
41 & 2.478 & 25,4 & 2,62 \\
\hline
\end{tabular}

Tabela 2. Continuação.

\begin{tabular}{|c|c|c|c|}
\hline Identificação & $\mathrm{RG}(\mathrm{kg} / \mathrm{ha})$ & PMG (g) & $\mathrm{PP}(\mathrm{g})$ \\
\hline 12 & 2.419 & $30,1 \mathrm{~S}$ & 2,59 \\
\hline 30 & 2.348 & 22,5 & 3,00 \\
\hline 24 & 2.301 & 25,8 & $3,84 \mathrm{~S}$ \\
\hline 15 & 2.238 & 24,3 & 1,91 \\
\hline 36 & 2.223 & 21,5 & 2,57 \\
\hline 32 & 2.206 & 23,6 & 2,99 \\
\hline 55 & 2.129 & 23,7 & 3,14 \\
\hline 44 & 2.121 & $19,4 \mathrm{I}$ & 2,22 \\
\hline 33 & 2.119 & $28,0 \mathrm{~S}$ & $4,28 \mathrm{~S}$ \\
\hline 52 & 2.087 & 27,3 & 2,86 \\
\hline 59 & 2.081 & 23,2 & 3,17 \\
\hline 63 & 2.056 & 26,9 & 2,72 \\
\hline 56 & 1.946 & 23,7 & 2,02 \\
\hline 60 & 1.936 & $27,9 \mathrm{~S}$ & 3,27 \\
\hline 6 & 1.919 & $32,1 \mathrm{~S}$ & 2,87 \\
\hline 13 & 1.900 & $29,0 \mathrm{~S}$ & 2,87 \\
\hline 37 & 1.883 & $20,3 \mathrm{I}$ & $1,82 \mathrm{I}$ \\
\hline 49 & 1.822 & 25,5 & $1,45 \mathrm{I}$ \\
\hline 22 & 1.809 & $19,0 \mathrm{I}$ & 2,36 \\
\hline 3 & 1.775 & 24,5 & 2,16 \\
\hline 8 & 1.744 & 24,3 & 1,98 \\
\hline 51 & 1.709 & 22,3 & $1,89 \mathrm{I}$ \\
\hline 53 & 1.677 & $17,9 \mathrm{I}$ & 2,40 \\
\hline 29 & 1.664 & 22,5 & 3,26 \\
\hline 45 & 1.656 & 24,1 & 3,01 \\
\hline 64 & 1.628 & 23,3 & 2,79 \\
\hline 27 & 1.614 & 23,6 & 2,65 \\
\hline 14 & 1.598 & $29,1 \mathrm{~S}$ & 2,06 \\
\hline 61 & 1.529 & 26,1 & 2,79 \\
\hline 58 & 1.465 & 23,8 & 2,19 \\
\hline 40 & 1.435 & 26,3 & 2,75 \\
\hline 23 & 1.430 & $20,7 \mathrm{I}$ & 2,78 \\
\hline 20 & 1.305 & 22,1 & 2,07 \\
\hline 48 & 1.261 & $19,4 \mathrm{I}$ & 1,91 \\
\hline 62 & 1.260 & $20,9 \mathrm{I}$ & 2,35 \\
\hline 10 & 1.259 & $20,8 \mathrm{I}$ & 1,91 \\
\hline 43 & 1.227 & 25,1 & 2,05 \\
\hline 11 & 1.190 & $27,6 \mathrm{~S}$ & 2,03 \\
\hline 67 & $1.125 \mathrm{I}$ & 21,4 & 1,95 \\
\hline 5 & $1.055 \mathrm{I}$ & $19,4 \mathrm{I}$ & 2,19 \\
\hline 34 & $889 \mathrm{I}$ & 21,8 & 1,90 \\
\hline 39 & $845 \mathrm{I}$ & 26,8 & $1,60 \mathrm{I}$ \\
\hline 38 & $785 \mathrm{I}$ & 22,9 & $1,73 \mathrm{I}$ \\
\hline 57 & $424 \mathrm{I}$ & 27,4 & $1,43 \mathrm{I}$ \\
\hline 42 & $347 \mathrm{I}$ & $16,4 \mathrm{I}$ & $1,05 \mathrm{I}$ \\
\hline Média & 1.960 & 24,2 & 2,6 \\
\hline Desvio-padrão & $770^{(1)}$ & 3,2 & 0,7 \\
\hline
\end{tabular}


Tabela 3. Incidência e severidade de ferrugem-da-folha e ferrugem-do-colmo, em diferentes estádios de desenvolvimento de aveia. Valores correspondentes à média de 20 unidades de observação dentro de cada repetição. FAEM/UFPel, 1998.

\begin{tabular}{|c|c|c|c|c|c|}
\hline \multirow[t]{2}{*}{ Identificação } & \multirow{2}{*}{$\begin{array}{c}\text { Elongação } \\
\text { FF Sev. }\end{array}$} & \multicolumn{4}{|c|}{ Floração $^{(1)}$} \\
\hline & & FF Inc. & FF Sev. & FC Sev. & FC Inc. \\
\hline & & & $(\%)$ & 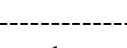 & \\
\hline 1 (UPF 16) & 5 & 90 & 30 & 1 & 20 \\
\hline 3 & 1 & 60 & 15 & 5 & 65 \\
\hline 4 & 1 & 40 & 10 & 60 & 100 \\
\hline 5 & 0 & 20 & 5 & 30 & 70 \\
\hline 6 & 1 & 40 & 10 & 20 & 80 \\
\hline 8 & 5 & 70 & 20 & 30 & 70 \\
\hline 9 & 1 & 20 & 5 & 20 & 10 \\
\hline 10 & 10 & 70 & 15 & 1 & 20 \\
\hline 11 & 5 & 40 & 10 & 1 & 5 \\
\hline 12 & 1 & 40 & 5 & 0 & 0 \\
\hline 13 & 5 & 50 & 10 & 1 & 5 \\
\hline 14 & 5 & 50 & 10 & 1 & 5 \\
\hline 15 & 1 & 10 & 1 & 0 & 0 \\
\hline 17 & 5 & 10 & 10 & 5 & 45 \\
\hline 18 & 1 & 70 & 25 & 10 & 30 \\
\hline 19 & 1 & 5 & 1 & 1 & 15 \\
\hline 20 & 5 & 40 & 30 & 1 & 10 \\
\hline 21 (UPF 16) & 10 & 60 & 30 & 5 & 50 \\
\hline 22 & 10 & 50 & 10 & 5 & 25 \\
\hline 23 & 5 & 5 & 5 & 5 & 15 \\
\hline 24 & 0 & 0 & 0 & 0 & 0 \\
\hline 25 & 0 & 0 & 0 & 0 & 0 \\
\hline 26 & 1 & 5 & 10 & 0 & 0 \\
\hline 27 & 0 & 0 & 0 & 1 & 35 \\
\hline 29 & 0 & 5 & 1 & 1 & 10 \\
\hline 30 & 0 & 10 & 5 & 1 & 5 \\
\hline 31 & 0 & 0 & 0 & 0 & 0 \\
\hline 32 & 0 & 0 & 0 & 0 & 0 \\
\hline 33 & 0 & 10 & 5 & 1 & 5 \\
\hline 34 & 10 & 80 & 100 & 1 & 75 \\
\hline 35 & 0 & 5 & 1 & 5 & 80 \\
\hline 36 & 5 & 10 & 10 & 5 & 85 \\
\hline 37 & 1 & 10 & 5 & 5 & 80 \\
\hline 38 & 5 & 30 & 5 & 5 & 75 \\
\hline 39 & 1 & 30 & 15 & 10 & 85 \\
\hline 40 & 1 & 40 & 10 & 10 & 95 \\
\hline 41 (UPF 16) & 10 & 60 & 40 & 1 & 10 \\
\hline 42 & 10 & 100 & 100 & 5 & 80 \\
\hline 43 & 5 & 40 & 10 & 20 & 100 \\
\hline 44 & 1 & 5 & 1 & 10 & 90 \\
\hline 45 & 10 & 10 & 40 & 5 & 50 \\
\hline 48 & 5 & 20 & 5 & 10 & 100 \\
\hline 49 & 1 & 5 & 1 & 1 & 70 \\
\hline 50 & 0 & 5 & 5 & 5 & 30 \\
\hline 51 & 0 & 10 & 1 & 1 & 10 \\
\hline 52 & 0 & 10 & 5 & 1 & 20 \\
\hline
\end{tabular}


Tabela 3. Continuação.

\begin{tabular}{|c|c|c|c|c|c|}
\hline \multirow[t]{2}{*}{ Identificação } & \multirow{2}{*}{$\begin{array}{c}\text { Elongação } \\
\text { FF Sev. }\end{array}$} & \multicolumn{4}{|c|}{ Floração $^{(1)}$} \\
\hline & & FF Inc. & FF Sev. & FC Sev. & FC Inc. \\
\hline & & & $(\%)$ & $--\cdot$ & 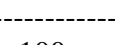 \\
\hline 53 & 0 & 5 & 1 & 50 & 100 \\
\hline 54 & 0 & 5 & 5 & 50 & 100 \\
\hline 55 & 0 & 5 & 1 & 20 & 100 \\
\hline 56 & 1 & 5 & 1 & 15 & 100 \\
\hline 57 & 5 & 30 & 5 & 20 & 90 \\
\hline 58 & 10 & 30 & 10 & 10 & 90 \\
\hline 59 & 1 & 20 & 5 & 10 & 90 \\
\hline 60 & 0 & 5 & 1 & 1 & 30 \\
\hline 61 (UPF 16) & 30 & 80 & 35 & 1 & 5 \\
\hline 62 & 15 & 30 & 15 & 5 & 70 \\
\hline 63 & 1 & 5 & 5 & 5 & 80 \\
\hline 64 & 1 & 60 & 20 & 5 & 90 \\
\hline 67 & 5 & 100 & 90 & 10 & 60 \\
\hline 68 & 0 & 5 & 1 & 40 & 100 \\
\hline 69 & 0 & 5 & 5 & 50 & 100 \\
\hline
\end{tabular}

(1) FF Sev.: porcentagem de severidade de ferrugem-da-folha; FF Inc.: porcentagem de incidência de ferrugem-da-folha; FC Sev.: porcentagem de severidade de ferrugem-do-colmo; FC Inc.: porcentagem de incidência de ferrugem-do-colmo.

outro lado, este tipo de manifestação não é característica nos genótipos 17 e 25 . Analisando o comportamento destas constituições genéticas, verifica-se que as linhas 68 e 69 responderam bem ao ambiente, dificultando o estabelecimento e ajuste do patógeno (Lehman \& Shaner, 1996). A linhagem 25 apresentou reação de resistência completa para FF, sem expressar pústulas, o que pode, a médio prazo, promover a quebra da resistência vertical, evidenciando a hipótese de complementaridade dos genes (Flor, 1971). Conforme Shaner (1996), a resistência parcial tem sido apontada como uma alternativa promissora para o controle de FF; desta forma, conforme o comportamento observado, as linhagens 68 e 69 poderão ser de grande utilidade para o melhoramento genético de aveia. Contudo, mesmo outros genótipos que não foram superiores quanto ao rendimento $\mathrm{e}$ demonstram progresso lento da moléstia podem ser utilizados como fonte de resistência. Estão representados os diferentes níveis de severidade de FF para a testemunha UPF 16, linhas "slow-rusting" e linhagens com reação de resistência completa (Figura 1).

Com relação à FC grande parte dos genótipos apresentou reação de resistência (Tabela 3). Vários expressaram nível baixo de severidade da ferrugemdo-colmo e da ferrugem-da-folha. O genótipo 25, inferior quanto ao rendimento, foi um destes.

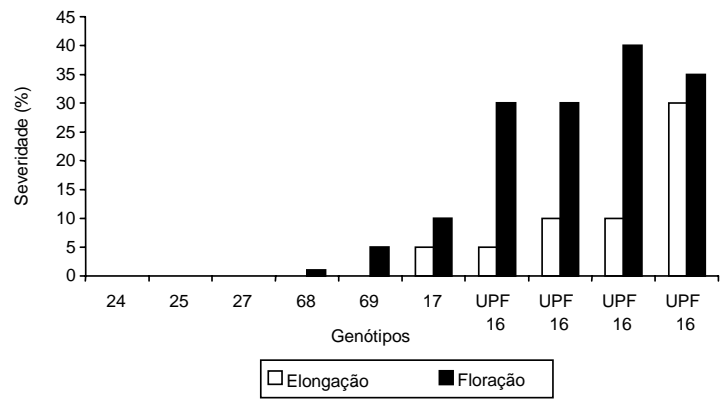

Figura 1. Relação entre diferentes tipos de reação à ferrugem-da-folha de genótipos de aveia: resistência completa $(24,25,27)$, resistência progressiva "slow rusting" $(68,69,17)$ e testemunha (UPF 16) quanto à severidade. Médias de quatro repetições. FAE/UFPel, 1998.

Os dados evidenciaram associação entre as moléstias, e podem ser confirmados pelos coeficientes de correlação, que indicam associação significativa entre as variáveis FF e FC, quanto ao critério severidade (Tabela 4). $O$ fato de que a alta incidência e severidade de FC sobre as linhagens 68 e 69 não tenham interferido na produtividade, sugere que a FC tem pouca influência sobre o RG (Tabela 3). No entanto, como dois dos componentes do rendimento (número de panículas e número de grãos) já haviam sido determinados no momento do surgimento das pústulas 
de FC (na maior parte no final do ciclo), a redução observada na área fotossintética pode não ter sido significativa e, portanto, ter mascarado o real efeito desta moléstia sobre o rendimento de grãos.

Os coeficientes de correlação entre a incidência e a severidade de ambas moléstias foram elevados e altamente significativos, com 0,78 para FF e 0,76 para FC (Tabela 4). Contudo, a correlação entre incidência $\mathrm{x}$ incidência e severidade $\mathrm{x}$ severidade da ferrugem-da-folha com ferrugem-do-colmo não demonstrou comportamento semelhante, já que as incidências apresentaram um coeficiente de correlação significativo, mas de baixa magnitude, e as severidades, um coeficiente não-significativo.

O rendimento de grãos apresentou correlação negativa com a incidência de ferrugem da folha $\left(\mathrm{r}=-0,34^{* *}\right)$, revelando um coeficiente de baixa magnitude, mas significativo (Tabela 4 e Figura 2). A baixa correlação encontrada pode ser atribuída aos genótipos, que, mesmo apresentando incidência moderada das moléstias, demonstraram alto rendimento. A manifestação de moléstias em níveis acentuados somente a partir da floração pode ter sido a causa de tal efeito.

Com relação à ferrugem-do-colmo, a correlação com o rendimento de grãos foi muito baixa e nãosignificativa $\left(r=-0,05^{\text {ns }}\right)$, revelando pouca importância em termos de perdas no rendimento (Tabela $4 \mathrm{e}$ Figura 2). As linhagens 68 e 69, com severidade de FC igual a $40 \%$ e $50 \%$, respectivamente, apresentaram os maiores rendimentos e contribuíram para a baixa magnitude da correlação.

O comportamento da severidade em razão da incidência foi semelhante em relação às duas molés-

Tabela 4. Coeficientes de correlação entre as variáveis rendimento de grãos (RG), incidência (IFF) e severidade (SFF) da ferrugem-da-folha, e incidência (IFC) e severidade (SFC) da ferrugem-do-colmo em genótipos introduzidos de aveia. FAEM/UFPeL, 1998.

\begin{tabular}{ccccc}
\hline Variáveis & IFF & SFF & IFC & SFC \\
\hline RG & $-0,34^{* *}$ & $-0,44^{* *}$ & $0,05^{\text {ns }}$ & $-0,16^{\text {ns }}$ \\
IFF & & $0,78^{* *}$ & $0,19^{\text {ns }}$ & $0,26^{\text {ns }}$ \\
SFF & & & $0,11^{\text {ns }}$ & $0,27^{*}$ \\
IFC & & & & $0,76^{* *}$ \\
\hline
\end{tabular}

ns Não-significativo. *Significativo a $5 \%$ de probabilidade pelo teste t. ${ }^{* * *}$ Significativo a $1 \%$ de probabilidade pelo teste $t$. tias, com tendência quadrática para a regressão e coeficientes de determinação de elevada magnitude (Figura 3). Na FF, foi observado um comportamento linear entre os parâmetros incidência e severidade praticamente até $80 \%$ de incidência, quando houve um acréscimo quadrático na severidade. Os dados con-

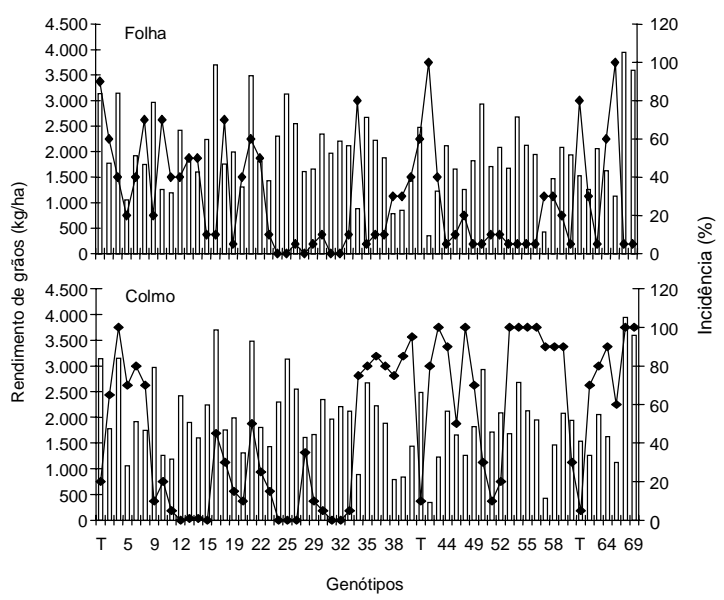

Figura 2. Rendimento de grãos $(\diamond)$ e incidência de ferrugem-da-folha e do colmo em genótipos introduzidos de aveia e na testemunha UPF 16 (T). FAE/UFPel, 1998.

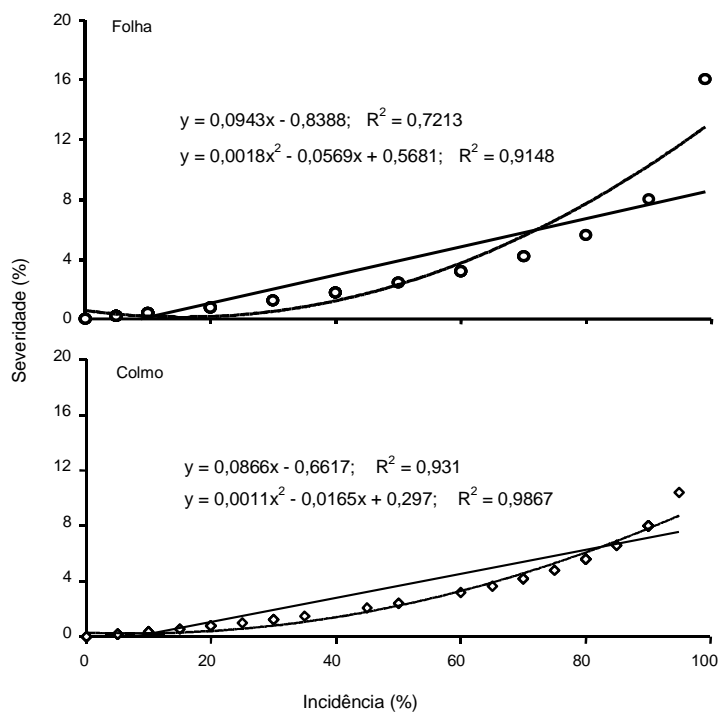

Figura 3. Relação entre incidência e severidade da ferrugem-da-folha (Puccinia coronata f. sp. avenae), e do colmo (Puccinia graminis f. sp. avenae), em genótipos de aveia (Avena sativa L.) introduzidos. FAE/UFPel, 1998. 
cordam com Amorim (1995), que relata a falta de relação linear entre incidência e severidade em níveis de epidemia avançado, pois nestas condições, a maioria das plantas já estão infectadas e não há praticamente crescimento espacial da moléstia (incidência), refletindo-se no aumento da intensidade de cobertura da área foliar (severidade).

A Figura 3, representando a FC, demonstra comportamento quase linear entre a incidência e severidade, decorrente dos baixos valores encontrados na porcentagem de área foliar infectada (severidade), o que reforça dados de Amorim (1995), de que este comportamento só é possível em valores reduzidos de severidade.

Os resultados sugerem estudos posteriores para a avaliação da magnitude e sentido da correlação entre a incidência e severidade no grupo de genótipos com resistência progressiva à ferrugem, separadamente das demais.

\section{Conclusões}

1. O diferente grau de correlação entre as moléstias ferrugem-da-folha e ferrugem-do-colmo com o rendimento permite estabelecer critérios diferenciados para a seleção de genótipos a campo.

2. A utilização do critério incidência para a determinação da intensidade das moléstias no campo é prática, e também eficiente, quando a intensidade da moléstia não for superior a $80 \%$.

\section{Referências}

AMORIM, L. Avaliação de doenças. In: BERGAMIN, A. F.; KIMATI, H.; AMORIN, L. (Ed.). Manual de fitopatologia: princípios e conceitos. 3. ed. São Paulo : Ceres, 1995. v. 1, p. 647-670.

BORÉM, A. Melhoramento de plantas. 2. ed. Viçosa : UFV, 1998. $453 \mathrm{p}$.

FLOR, H. H. Current status of the gene for gene concept. Annual Review Phytopathology, Palo Alto, v. 9, p. 275-296, 1971.

FORSBERG, R. A.; McDANIEL, M. E.; TROMBETTA, R.; WEAVER, S. H. Breeding oat cultivars suitable for production in developing countries. Madison : University of Wisconsin, 1998. $130 \mathrm{p}$.

JAMES, W. C.; SHIH, C. S. Relationship between incidence and severity of powdery mildew and leaf rust on winter wheat. Phytopathology, St. Paul, v. 63, p. 183-187, 1973.

LARGE, E. C. Growth stages in cereals, illustration of Feekes scale plant. Phytopathology, St. Paul, v. 3, p. 128-129, 1954.

LEHMAN, L. S.; SHANER, G. Genetic variation in latent period among isolates of Puccinia recondita f. sp. tritici on partially resistant wheat cultivars. Phytopathology, St. Paul, v. 86, p. 633-641, 1996.

MARTINELLI, J. A.; FEDERIZZI, L. C.; BENNEDETTI, A. C. Redução do rendimento de grãos de aveia em função da severidade da ferrugem da folha. Summa Phytopathologica, Piracicaba, v. 20, p. 116-118, 1994.

REIS, E. M. Importância do controle de doenças dos cereais de inverno. Correio Agrícola, São Paulo, n. 1, p. 2427, 1998.

REIS, E. M.; CASA, R. T.; FORCELINI, C. A. Relação entre a severidade e a incidência da ferrugem da folha do trigo, causada por Puccinia recondita f. sp. tritici. Fitopatologia Brasileira, Brasília, v. 21, p. 369-372, 1996.

ROELFS, A. P.; SINGH, R. P.; SAARI, E. E. Las royas del trigo: conceptos y métodos para el manejo de esas enfermedades. México : CIMMYT, 1992.81 p.

SHANER, G. Breeding for partial resistance in oat to rusts. In: INTERNATIONAL OAT CONFERENCE, 5. , 1996, Saskatoon. Proceedings... Saskatoon : Saskatoon University, 1996. p. 307-313.

SIMONS, M. D.; MURPHY, H. C. Oat diseases. In: COFFMAN, F. A. Oats and oat improvement. Madison : American Society of Agronomy, 1961. p. 330-390. (ASA Agronomy, 8).

TOMERLIN, J. R.; HOWELL, T. A. DISTRAIN: a computer program for training people to estimate severity on cereal leaves. Plant Disease, St. Paul, v. 72, n. 5, p. 455459, 1988.

ZIMMER, D. E.; SHAFER, J. F.; PATTERSON, F. L. Mutations for virulence in Puccinia coronata. Phytopathology, St. Paul, v. 53, p. 171-176, 1963. 